\title{
DESIGNING A VIRTUAL REALITY ENVIRONMENT FOR TRAINING OF MEDICAL STUDENTS ON PATIENT SAFETY CULTURE
}

\author{
Lopez $\mathrm{M}^{1,2^{*}}$, Astengo $\mathrm{C}^{3}$ and Lamus $\mathrm{F}^{4}$ \\ ${ }^{I}$ Tecnologico de Monterrey, Escuela de Medicina y Ciencias de la Salud, Mexico \\ ${ }^{2}$ Writing Lab, Institute for the Future of Education, Tecnologico de Monterrey, \\ Monterrey, Mexico \\ ${ }^{3}$ Tecnologico de Monterrey, Mexico \\ ${ }^{4}$ Universidad de la Sabana, Colombia
}

\begin{abstract}
In medicine, the awareness of reducing medication errors and risk situations for patients has increased in recent years, due to different driving forces such as patient advocate movements, and quality management strategies of health centers and regulatory bodies. However, this awareness should be reflected in the integration of strategies to prevent errors and risks by training medical students, residents, and specialists in patient safety principles. The inclusion of technologies for tridimensional visualization, such as virtual reality enables the development of innovative training proposals that contribute to a patient safety culture. The objective of this project was to design a virtual reality environment for the training on patient safety culture by triangulating the perspectives of teachers, the hospital, and the school of medicine. The development consisted of the phases of planning, design, and implementation. Planning referred to the development of learning objectives and conceptualization of scenarios. The design consisted of the technical exploration of the different tools, and the iteration on the generation of a working prototype. As a result, a virtual setting was developed for medical students to familiarize themselves and understand the environment and the processes of quality care. The reported experience proposes key elements for new developers to consider, the link to the needs of the organization, and the technical feasibility of the systems that are now available in the market.
\end{abstract}

Keywords: higher education, educational innovation, educational technology, virtual reality, medical education, patient safety

\section{Introduction}

The constant changes in disease models and the transformation of medical practice demands that medical schools prepare the student not only to master scientific principles and treatment of diseases but also demonstrate the acquisition of transversal skills such as communication and working in teams, as well as professionalism attributes of medicine. These skills, often overlooked, are the differentiator factors of an excellence culture.

Practices in simulated environments allow the optimization of students' abilities by providing motivation and direction for future learning (Epstein \& Hundert, 2002). Through which students can obtain the practice and evaluation of technical procedures, as well as clinical skills and team training to improve performance in complex environments. Practicing in these environments fulfills a 
commitment as well with patients to offer the best care possible through having the most prepared person to do so.

\section{Patient safety culture}

Practicing an unsafe medical practice exposes the patient to adverse outcomes, such as disability or death. According to the Institute of Medicine report, 33.6 million hospitalizations occur each year only in the United States, of which about 98,000 deaths result from preventable medical errors (Kohn, Corrigan, \& Donaldson, 2000). Among the main causes of death, medical error is number eight, even above AIDS, car accidents, and breast cancer (Escalante \& Matos, 2013).

For the year 2001, six International Patient Safety Goals were declared (James, 2013): Correctly identify patients, Improve effective communication, Improve the safety of high-risk medications, Guarantee surgeries in the correct place, with the procedure and the right patient, Reduce the risk of infections associated with medical care, Reduce the Risk of Injury to the patient due to falls. In Mexico in 2001, as part of the presentation of the National Development Plan 2001-2006, a new vision was released where the country is capable of responding with quality and respect to the needs and expectations of its citizens, through instances where complaints and mechanisms for citizen participation are presented and resolved (CONAMED, 2001).

One of these commitments triggers the emergence of the National Crusade for the Quality of Health Services to guarantee dignified treatment, complete information, and timely care. Respect for the rights and dignity of patients, fostering a culture of service, and the guarantee of confidentiality triggered the promulgation of the Charter of General Rights of Patients. This effort was led by the National Commission for Medical Arbitration (CONAMED for its initials in Spanish), together with more than a thousand actors from civil society and health organizations, among which the Undersecretariat of Innovation and Quality, the National Bioethics Commission, the Commission National Human Rights, the Federación Nacional de Colegios de Profesión Médica, the Subdirección General Médica, and the Comisión Interinstitucional de Enfermería y la Dirección General de Asuntos Jurídicos of the Ministry of Health (Profeco, 2005).

The principle of doing no harm is considered fundamental in medical practice, which is why it is necessary to guarantee patients' safety, ensuring that doctors have the knowledge and competence to make an accurate diagnosis and an effective course of treatment. Teaching in medicine is guided by a different educational model than other professions; without a patient there is no clinical practice, that is, there would be no learning experiences (Segura-Azuara, Valencia Castro \& Lopez, 2018). Therefore, teaching in clinical settings is essentially opportunistic, taking advantage of learning experiences as they are presented. Students face different environments and medical cases, so they are trained under different models and forms and face different challenges in their journey as learners in a highly complex setting (Valencia Castro, Tapia Vallejo \& Olivares Olivares, 2019).

The awareness of reducing medication errors and risk situations for the patient has increased in recent years, due to increasing pressure from health centers, regulatory and certification bodies, and civil society. However, this awareness should be reflected in the integration of strategies within the curriculum that trigger the motivation and involvement of students to reduce risks for patients, in 
settings in which they can learn from the mistakes in a safe environment for learning (Ziv, Ben-David \& Ziv, 2005).

\section{Simulation in medicine}

The medical education community commonly uses the Miller Pyramid to discuss a student's proficiency level. At the base of the pyramid, we can find the know that means that students the theoretical knowledge about the subject. At the second level, we find knowing how, which is how to apply this knowledge. The third level involves showing how where the student can demonstrate in simulated environments what they can do. And finally, at the peak of the pyramid, there is doing, which is when it can be carried out in real practice. One of the strategies in medicine to offer learning experiences to students has been the incorporation of simulation as a technique to replace or replicate in an artificial environment, the interaction with the patient (Weller, 2004). This allows the student to move from knowing how-to showing how.

Simulation as a teaching strategy provides a learning opportunity in a programmed, guided, and interactive way (Aggarwal, et al., 2010). The simulation allows the standardization of the experience and the design of a specific scenario to achieve learning. This process can be repeated as many times as necessary for the learning objective to be achieved. While the idea of simulation provides a safe alternative to accelerate the learning curve, uptake has been slow due to skepticism, lack of communication, and lack of research documenting its benefits (Rosen, 2008).

Various studies argue that the skills developed in students in simulated practice are not directly transferable in a real environment (Langhan, 2008; Lamb, 2007). They attribute their concerns to the lack of realism in the practices, and how this contributes to the student's failure to commit to the entire experience. It is necessary to integrate realism into simulated practices so that they faithfully recreate the experiences that the student would be subjected to in a hospital environment. This demands the design of teaching models, the development of standardized simulated practices, and the training of the human resource that would implement the experience. At the same time, it shows the need to allocate technology and facilities in hospitals and clinics to constantly develop these teaching activities. In such a way that clinical and academic staff systematically carry out simulated practices according to the level of training and competence of each student, where monitoring programs are also included to ensure compliance with international objectives and standards for the safety of the patient.

\section{Building innovative training including simulation}

The first efforts to build a simulator date back to 1930 when Edwin Link created the Link Flight Trainer. The flight simulator was trying to find an easier and safer way to train a person seeking to obtain a pilot license. This training model allowed the trainee to improve or gain flying skills without ever leaving the ground. Initially, it was used as an attraction in amusement parks due to the novelty it represented; however, it impacts globally (ASME International, 2000). In 1934, after numerous fatal accidents, the United States Army purchased 6 simulators to train its pilots in flying skills and control of the scoreboard (Rosen, 2008). Years later, with the First World War, this technology increased its demand, around 10,000 simulators were used for the training of 500,000 pilots (ASME International, 2000). According to the training needs, the advance in technology and complexity of the simulators 
also advanced. They were not only used for handling aircraft, but also for heavy artillery and observation modules.

The first efforts of simulation in medical education can be considered as those made by Asmund Laerdal in the last century. He was a toy publisher and producer and developed the Resusci-Anne model (Bradley, 2006). This manikin was designed to practice resuscitation training maneuvers.

In a second effort, we found the life-size mannequin made by Hartford Hospital, named Mrs. Chase. This model included an arm available for catheterization and injections. In addition to a set to apply cannulas and urological and rectal procedures. Years later, in 1960, more sophisticated models were created such as the SimOne, developed by Abrahamson and Denson at Harvard University (Bradley, 2006). This manikin had breathing, heartbeat, pulse, blood pressure, opened and closed its mouth, blinked, and responded to intravenous medications and mask-administered gases. However, it was not widely accepted, because the cost of the technology in its time was very high, and consequently, only one prototype was produced.

In 1970, the University of Miami developed the Cardiology phantom called Harvey (Aggarwal, et al., 2010). Which was a simulator that integrated information related to very strange heart diseases.

Another effort is the one led by Gaba in 1980. He developed a simulation environment for anesthesia training called CASE which was later marketed as Medsim (Bradley, 2006). Also Good and Gravenstein's group developed one for the anesthesia area, called GAS which was later marketed as Medical Education Technologies Inc., or METI for its acronym in English (Bradley, 2006).

The systematic approach to these scenarios, through the inclusion of technology, provides a safe environment to achieve mastery of skills (Segura-Azuara, Eraña-Rojas \& Lopez, 2018). Some developments are targeted through disciplinary fields, for example in surgical settings, and others in the skills that are developed like communication or team training. Emergent technology poses new solutions that are cost-effective and can be widely implemented one of these technologies that offer a three-dimensional visualization of an environment is virtual reality (VR).

VR is defined as an alternative environment composed of scenes that alter or replace reality, through natural interaction with objects in the environment (Psotka, 1995). Some of the most popular platforms are Microsoft Hololens, Oculus Rift, Samsung Gear VR, and Google Cardboard (Goh, 2016). These viewers vary in their experience through the interaction of controls, cost, and the operating system they are compatible with for scenario development. As these technologies gain acceptance by the general public, their uses in educational settings are increasing.

For example, Stojšić et al. (2016) describe the incorporation of VR in teaching geography. Leveraging the use and development of technologies, the authors discuss cardboard head-mounted displays that become a low-cost alternative to introduce these technologies in education. The authors build on the experience first commenced by Google on developing expeditions programs where laypeople could massively utilize the Google platform in education.

Hodgson et al. (2019) describe the development and assessment of two different virtual settings, one for a pharmacology class and the other towards ecotourism. The authors incorporated the use of $360^{\circ}$ 
videos to transcend the physical boundaries of the university. Students in the classroom explored these settings through embedded content that allowed them to engage in deeper cultural and historical understanding.

Other authors have focused on defining educational models that describe the technology and the instructional design that supports the process of a VR setting for education. Chen (2009) developed a model that identifies the distinct features in: instructional design and development, ongoing participatory team involvement, non-linear and dynamic interaction. Particularly for medical education settings, these technologies can prove an effective way to train students in immersive environments through highly engaging learning scenarios (Lopez, Carrillo, Nigenda, Treviño, ValdezGarcía \& Carrion, 2019). Therefore, this project's objective was to design a virtual reality environment for the training on patient safety culture by triangulating the perspectives of teachers, the hospital, and the school of medicine.

\section{Methods}

To contrast and integrate the perspectives of teachers, hospitals and the school of medicine, the development of the environment consisted of planning and design phases (figure 1).

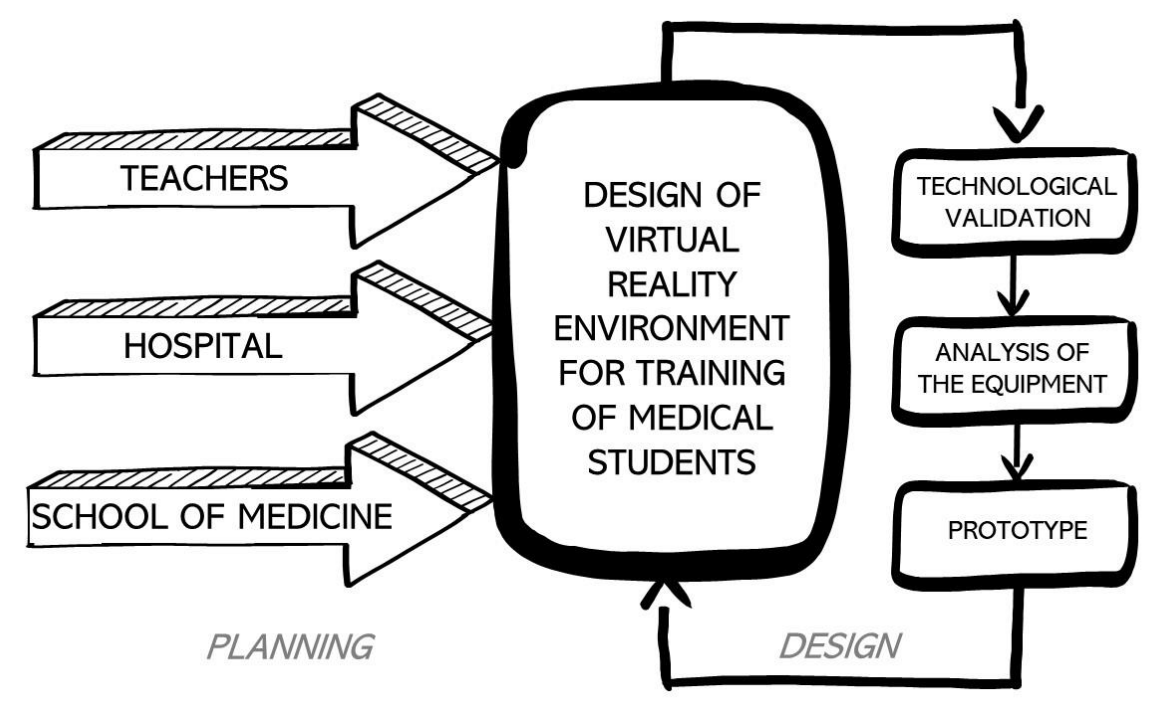

Figure 1: Process of design of virtual reality environment for the training of medical students

The planning contemplated the definition of the elements that would be part of the training environment was done through the alignment of 3 perspectives: teachers, hospital, and school. The teachers' perspective was collected by applying the Mira et al. instrument (2015) that assesses the attitudes and knowledge in patient safety. This instrument has been used in a similar context of both undergraduate training for physicians and nurses in Spain and America Latina. The original version is comprised of 21 items cataloged in five factors: openness in communication, proactive attitude to avoid risks in security, awareness of error, understanding the human factor, and system complexity and interrelationship. In the previous implementation, the reliability indexes on the five factors were above 0.7 , which is considered acceptable. A convenience sample strategy of 35 participants assessed the attitudes and knowledge of medical students regarding patient safety principles. 
To understand the hospital perspective, structured interviews were conducted with the Operations Director and the supervisor of clinical students in the Quality Management department of a hospital. The interviews were 80 minutes long, were recorded with the consent of the participant, and then transcript verbatim.

To understand the medical school perspective a documental analysis was performed of the medical program curriculum.

The design included technological validations and analysis of the equipment that would favor the experience. In this part, the research team integrated by engineers, physicians, and educators performed an analysis to consider the graphics, updates to the development platform, price, portability, intuitive interaction through the attached controls, and the response given to the user (table $1)$.

\section{Results}

The results of the teachers' perspective on students' knowledge of patient safety principles show that the lowest perception of competence was found on the coping strategies of students to deal with the feelings generated when making a mistake, studying knowing how to property inform patients who have suffered harm as a result of an error, and students have acquired the skills to report a problem to colleagues and supervisors, with a mean of 2.1, 2.4, and 2.6, respectively. The latter refers to the understanding of the procedures that need to be carried out when unsafe situations are present. The highest results were found on student witnessing another student performed something unsafe to a patient, students witnessing their peers performing risky procedures to patients, and seeing their supervisors doing the same, with a mean of 4.6, 4.4, and 4.3, respectively. These results prioritize the need for students to engage in training to understand and navigate the complexity of the clinical settings with confidence. The implementation of strategies to better prepare them in patient safety culture.

Table 1: Understanding teachers' perspective

\begin{tabular}{|c|c|c|}
\hline Factors & Item & Mean \\
\hline \multirow{8}{*}{$\begin{array}{l}\text { Openness in } \\
\text { communication }\end{array}$} & $\begin{array}{l}\text { The students know how to properly inform patients who have suffered harm as } \\
\text { a result of an error. }\end{array}$ & 2.4 \\
\hline & The students have learned how to assess risks the risks to patient safety. & 3.3 \\
\hline & The students have learned what to do if they make a mistake. & 2.7 \\
\hline & $\begin{array}{l}\text { The students discuss with their instructors or supervisors when there is an } \\
\text { unsafe situation that they have observed. }\end{array}$ & 3.1 \\
\hline & $\begin{array}{l}\text { The students have acquired the skills to report a problem to colleagues and } \\
\text { supervisors. }\end{array}$ & 2.6 \\
\hline & $\begin{array}{l}\text { The students have coping strategies to deal with the feelings generated when } \\
\text { making a mistake. }\end{array}$ & 2.1 \\
\hline & $\begin{array}{l}\text { The students have learned how to better communicate with patients to prevent } \\
\text { medication errors. }\end{array}$ & 3.1 \\
\hline & $\begin{array}{l}\text { The students carry out clinical practices in a hospital where a non-punitive } \\
\text { culture is promoted, in which if a mistake were to happen, they would know } \\
\text { how to prevent it from happening again. }\end{array}$ & 2.8 \\
\hline Proactive attitude & The professors have given the students lectures on what to do to avoid common & 3.5 \\
\hline
\end{tabular}


to avoid safety mistakes in their professional practices.

risks

The students are familiar with the steps that must be taken to prevent a medical error to happen again the future.

The students have discussed frequent common mistakes with their teachers and have shared possible recommendations to avoid them.

$\begin{array}{ll}\text { The students know the objectives and priorities on making patient care safer. } \quad 3.4 & 3.7\end{array}$

\begin{tabular}{llll} 
& I have witnessed a student done something that was not safe for the patient. & 4.6 \\
\cline { 2 - 3 } $\begin{array}{l}\text { Understanding of } \\
\text { human factor }\end{array}$ & $\begin{array}{l}\text { The students have seen their peers performing a risky procedure to a patient. } \\
\text { patient. }\end{array}$ & 4.4 \\
\cline { 2 - 4 }
\end{tabular}

The students know the safety standards that they must follow with patients on the different services where they perform clinical rotations.

The students understand the importance of following a protocol to improve quality care.

The students understand the importance of using the proper treatments for

System patient safety.

complexity and interrelationship

\begin{tabular}{lc}
\hline The students know the importance of proper technique for hand hygiene. & 4.2 \\
\hline $\begin{array}{l}\text { The students consider that most errors in patient care are impossible to avoid. } \\
\text { The students consider that the protocols implemented to guarantee patient }\end{array}$ & 3.3 \\
safety are obsolete. & 3.4
\end{tabular}

The vision of the hospital emphasized that students ignore the processes specifically on patient safety of the hospital, for example, the distinction of sterile areas marked on the floor, and the procedures on reporting a medical error or a quasi-error (table 2).

Table 2: Hospital concerns and identified needs of training for students

\begin{tabular}{ll}
\hline Themes & Concerns of participants \\
\hline Regulations and & "Students often lack the knowledge to know whom to call, where to report and what \\
procedures & should be done in cases of medical error or a quasi-error" \\
& "I do not think they need to know all the details that NOMs and laws provide but they \\
& need to see its translation to the context [in their hospital]" \\
& "Every hospital has its procedures, you familiarize with it while working, mostly by \\
& needing to solve the problems that emerge" \\
& "[the students] need to even know where things are in an OR [operating room] and how \\
& their displacements affect other people in the room. For example the marks in the floor or \\
the distinction of sterile areas" & "It's the culture where they are not on top of the hierarchy in the hospital, with us [private \\
& teaching hospital] they see a reality, that might not be their professional reality after they \\
graduate" & "strategies need to focus on motivating them to do the right thing even before errors \\
Insight on how" & "a more hands-on training not reading textbooks, something that would give them a name \\
to respond & and face to the problem we are trying to solve" \\
"It is not what they learn in the classroom that is not as strong and transformative as what \\
they experience when they visit the hospital" \\
"...it is what they see their peers and attending doing what will stick on the acceptable \\
things to do" \\
"every person in the team has a role in care, and also a responsibility within the system of \\
the hospital"
\end{tabular}


Regarding the vision of the school of medicine, contents were identified of a course on Quality Healthcare and Patient Safety. A part of the objectives of the course, students develop the following competencies:

- define basic concepts of quality and patient safety

- identify key components of safety culture in healthcare

- apply methods and tools for collecting, analyzing, and using quality information to improve patient safety

- design strategies to promote a safety culture and clinical management of risks

- identify the role of the health professional in patient safety.

As part of the technological design process, several systems were considered for the analysis, particularly the HTC Vive and Oculus system, the latter in its variations of OculusGo and OculusRIFT. The priorities of the analysis were graphics, development and platform updates, portability, intuitive interaction with handheld devices or controllers, and user responsiveness (Table $3)$.

Table 3: Analysis and selection of virtual reality systems

\begin{tabular}{|c|c|c|c|c|}
\hline Factor & Description & HTC Vive & OculusGo & OculusRIFT \\
\hline Graphics & $\begin{array}{l}\text { Image and video quality that can } \\
\text { be viewed through this interface }\end{array}$ & 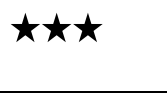 & $\star \star \star$ & 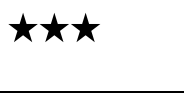 \\
\hline $\begin{array}{l}\text { Development } \\
\text { platform updates }\end{array}$ & $\begin{array}{l}\text { Frequency change supplier } \\
\text { development platform, which } \\
\text { makes frequently due migrate or } \\
\text { upgrade work. }\end{array}$ & 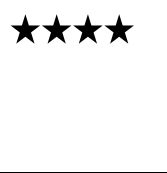 & $\star \star$ & $\star \star$ \\
\hline Price & $\begin{array}{l}\text { Investment to be made for the } \\
\text { acquisition of computer } \\
\text { equipment, viewer, and } \\
\text { minimum peripheral devices for } \\
\text { its operation }\end{array}$ & $\star$ & 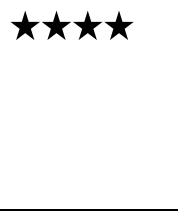 & 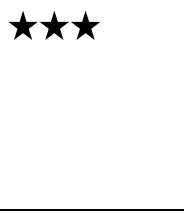 \\
\hline Portability & $\begin{array}{l}\text { Possibility of moving the } \\
\text { equipment to another space } \\
\text { without requiring the support of } \\
\text { a technical support team }\end{array}$ & $\star \star \star$ & 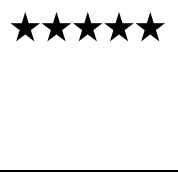 & $\star \star \star$ \\
\hline $\begin{array}{l}\text { Intuitive } \\
\text { interaction with } \\
\text { handheld devices } \\
\text { or controllers }\end{array}$ & $\begin{array}{l}\text { Recognition of participant } \\
\text { responses through touch, } \\
\text { movement, and vision, for the } \\
\text { manipulation of virtual objects, } \\
\text { application pause, and } \\
\text { navigation in the environment. }\end{array}$ & 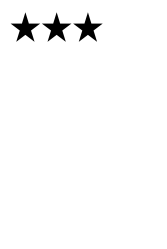 & $\star$ & 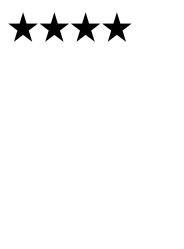 \\
\hline $\begin{array}{l}\text { User } \\
\text { responsiveness }\end{array}$ & $\begin{array}{l}\text { Detection speed of response to } \\
\text { an indication by the user. }\end{array}$ & 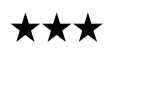 & 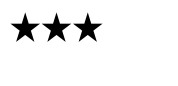 & 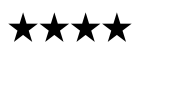 \\
\hline
\end{tabular}

The compatibility and massification of the experience made the team decide to continue with the OculusRIFT system, accepting some limitations with this choice, such as the portability of the system. 
The virtual learning environment that was designed depicted a place for students to understand the physical space as well as the processes that are part of the environment (figure 2).

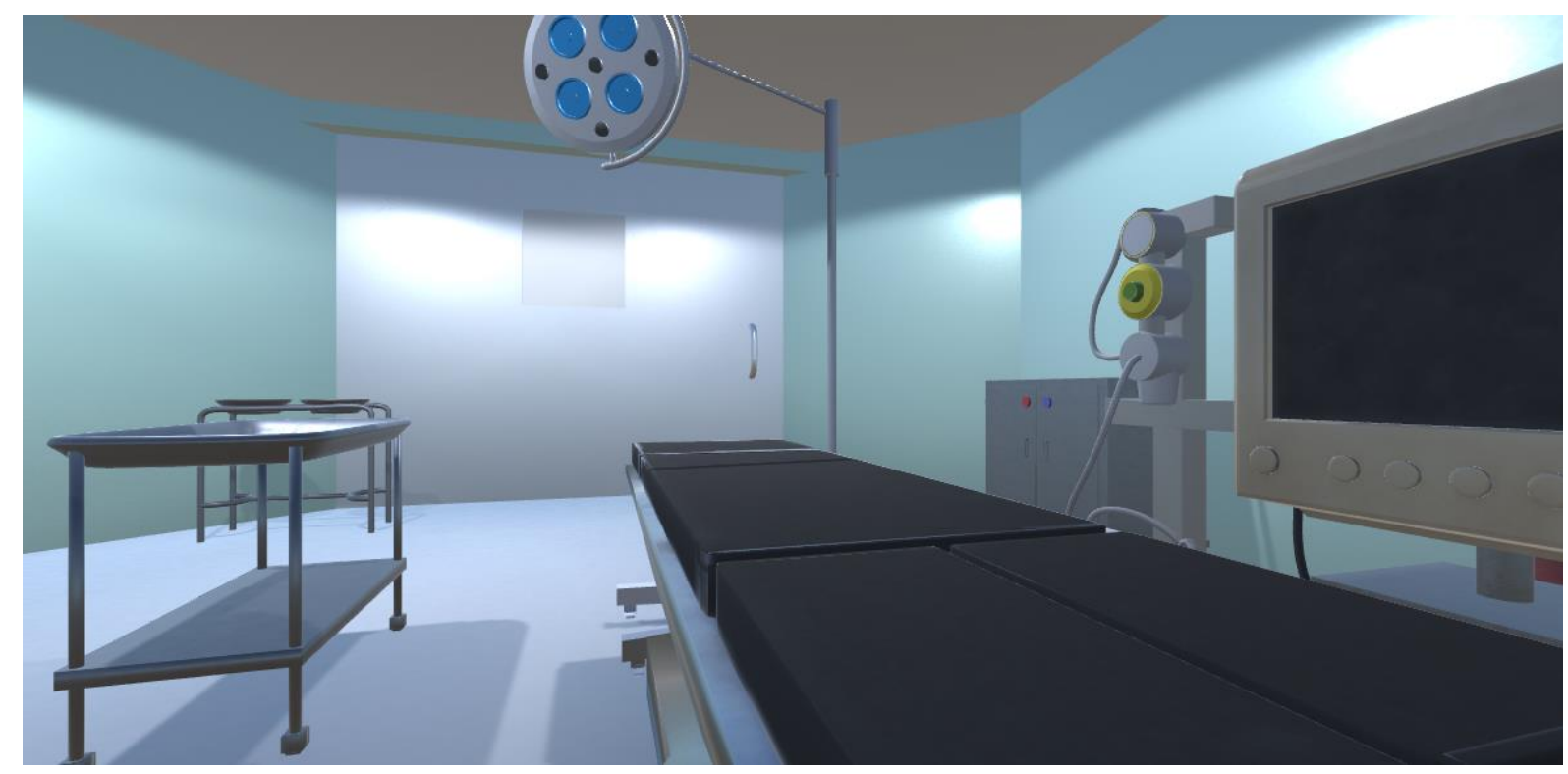

Figure 2: Virtual reality surgical environment

Creating these environments offers many benefits for learners, especially if an educational objective is clearly stated. As Pottle (2019) eloquently described, VR offers a new area for clinical simulation to continue growing. A few years ago, there was a clear distinction between what was considered simulation and what educational technology could do. However, as we understand the learning needs, the boundaries of disciplinary frameworks are more diffused. Viera de Faria et al. (2016) experienced the same challenge when developing a stereoscopic anatomy simulator using VR. Although a clear need was identified for interactive and pedagogical support applications, there is still a belief that these technologies are not comparable to the actual practice. Studies comparing available products and methodologies to contrast the gains in learning and its translation to practice can diminish those fears.

An apparent constraint is still the budget dedicated to the development of a realist immersive scenario. However, if these costs are compared with other such as the investment needed to set a laboratory or the commitment towards patients and their families, these delivery formats offer cost-effective, repeatable, and standardized training. One proposal that educators and institutions should invest time and money to explore.

\section{Conclusions}

A relatively new movement in medical education has to do with an educational reform that tries to move the medical student from being overloaded with large amounts of information, at the expense of lack of knowledge and practice in clinical settings, to a program that fosters environments to truly develops clinical skills early at the undergraduate level. However, even towards the postgraduate and continuing medical education, the development of tools for training and reassessment of competencies is also a need. 
The involvement of key actors dictates the prioritization of innovative strategies for training such as simulation in the public interest, such as civil liability insurers, professional societies, accrediting organizations, and government agencies. And their interest is varied, for example, the societal expectations, professional regulations, or political responsibility. The former has to do with the little time or opportunities in which students can train the complex procedures and processes.

The presented project builds on the experience of medical educators of migrating to new frontiers on their roles, doing their first projects where they need to work with designers, programmers, and instructional designers. Although it was a complex project at the beginning targeting the innovation through structured design is the most efficient approach (Chen, 2009). A need to solve still is how these developments can be aligned with sustainable design practices that also allow the democratization of learning resources; an approach could be the development with low-cost proposals that leverage, for example of cardboard head-mounted displays (Stojšić et al., 2016).

The creation of new learning environments must be based on developments that start from an educational problem or need towards a specific proposal linked to a learning objective; otherwise, it becomes a passing educational trend. The reported experience evaluates key elements for developers: the link with the needs of an organization and the technical feasibility of the available systems.

\section{References}

Aggarwal, R., Mytoon, O. T., Derbrew, M., Hananel, D., Heydenburg, M., Issenberg, B., . . Reznik, R. (2010). Training and simulation for patient safety. Qual Saf Health Care, 34-43. DOI: 10.1136/qshc.2009.038562

ASME International. (May 2000). The Link Flight Trainer. Binghamton, NY, US.

Bradley, P. (2006). The history of simulation in medical education and possible future directions. Medical Education, 40, 254-262. DOI: 10.1111/j.1365-2929.2006.02394.x

Chen, C. J. (2010). Theoretical bases for using virtual reality in education. Themes in science and technology education, 2(1), 71-90.

Cioffi, J. (2001). Clinical simulations: development and validation. Nurse Education Today, 21, 477486. DOI: $10.1054 /$ nedt.2001.0584

CONAMED. (December 2001). Carta de los Derechos Generales de los Médicos. México.

Epstein, R., \& Hundert, E. M. (2002). Defining and Assessing Professional Competence. Journal of Americal Medical Association, 287, 226-235. DOI: 10.1001/jama.287.2.226

Escalante, R., \& Matos, G. (2013). Simulación clínica: seguridad y calidad para el paciente. Interciencia, 4(1), 41-48.

Goh, P. (2016). Technology-enhanced learning in Medical Education: What's new, what's useful, and some important considerations. MedEdPublish, 5(3), $16 . \quad$ DOI: https://doi.org/10.15694/mep.2016.000102

Hodgson, P., Lee, V., Chan, J., Fong, A., Tang, C., Chan, L., Wong, C. (2019) Immersive Virtual Reality (IVR) in Higher Education: Development and Implementation. In: tom Dieck M., Jung T. (eds) Augmented Reality and Virtual Reality. Progress in IS. Springer. https://doi.org/10.1007/978-3030-06246-0_12

Kohn, K., Corrigan, J., \& Donaldson, M. S. (2000). To err is human: Building a safer health system. Washington, U.S.: National Academy Press. 
Lamb, D. (2007). Could simulated emergency procedures practiced in a static environment improve the clinical performance of a Critical Care Air Support Team (CCAST)? A literature review. Intensive Crit Care Nurs, 23(1), 33-42. DOI: 10.1016/j.iccn.2006.07.002

Langhan, T. S. (2008). Simulation training for emergency medicine residents: time to move forward. Canadian Journal of Emergency Medicine, 10(5), 467-469. DOI: 10.1017/s1481803500010575

Lopez, M., Carrillo, J.G., Nigenda, J. P., Treviño, R., Valdez-García, J. E., \& Carrión, B. (2019, October). Assessing the effectiveness of teaching anatomy with virtual reality. In Proceedings of the $201911^{\text {th }}$ International Conference on Education Technology and Computers (pp. 43-46). https://doi.org/10.1145/3369255.3369260

Mira, J.J., Navarro, I.M., Guilabert, M., Poblete, R., Franco, A.I., Jiménez, P. (2015). A Spanishlanguage patient safety questionnaire to measure medical and nursing students' attitudes and knowledge. Rev Panam Salud Publica, 38(2), 110-119.

Pottle, J. (2019). Virtual reality and the transformation of medical education. Future Healthc J, 6(3), 181-185.

Profeco. (February 2005). Los pacientes también tienen derechos. Consumidor, págs. 69-70.

Psotka, J. (1995). Immersive training systems: Virtual reality and education and training. Instructional Science, 23, 405-431. https://www.jstor.org/stable/23370939

Rosen, K. R. (2008). The history of medical simulation. Journal of Critical Care, 23, 157-166. DOI: 10.1016/j.jcrc.2007.12.004

Segura-Azuara, N., Valencia Castro, J. L., \& Lopez, M. (2018). Desarrollo del pensamiento crítico mediante la simulación de alta fidelidad con estudiantes de medicina. Investigación en educación médica, 7(28), 55-63. http://dx.doi.org/10.22201/facmed.20075057e.2018.28.1749

Segura-Azuara, N., Eraña-Rojas, I. E., \& Lopez, M. (2018). High-fidelity simulation in pathophysiology courses with medical students. Educación Médica, 19(6), 355-358. https://doi.org/10.1016/j.edumed.2017.12.003

Stojšić, I., Ivkov Džigurski, A., Maričić, O., Ivanović Bibić, L., \& Đukičin Vučković, S. (2017). Possible Application of Virtual Reality in Geography Teaching. Journal of Subject Didactics, 1(2), 83-96. https://doi.org/10.5281/zenodo.438169

Valencia Castro, J. L., Tapia Vallejo, S., \& Olivares Olivares, S. L. (2019). La simulación clínica como estrategia para el desarrollo del pensamiento crítico en estudiantes de medicina. Investigación en educación médica, 8(29), 13-22. https://doi.org/10.1016/j.riem.2016.08.003

Viera de Faria, J.W., Teixeira, M. J., Sousa Júnior, L.M., Otoch, J.P., Figueiredo, E.G. (2016). Virtual and stereoscopic anatomy: when virtual reality meets medical education. Journal of Neurosurgery $J N S, 125(5), 1105-1111$.

Weller, J. M. (2004). Simulation in undergraduate medical education: bridging the gap between theory and practice. Medical education, 38(1), 32-38. DOI: 10.1111/j.1365-2923.2004.01739.x

Ziv,A., Ben-David, S., \& Ziv, M. (2005). Simulation-based medical education: an opportunity to learn from errors. Medical Teacher, 27(3), 193-199. DOI: 10.1080/01421590500126718 